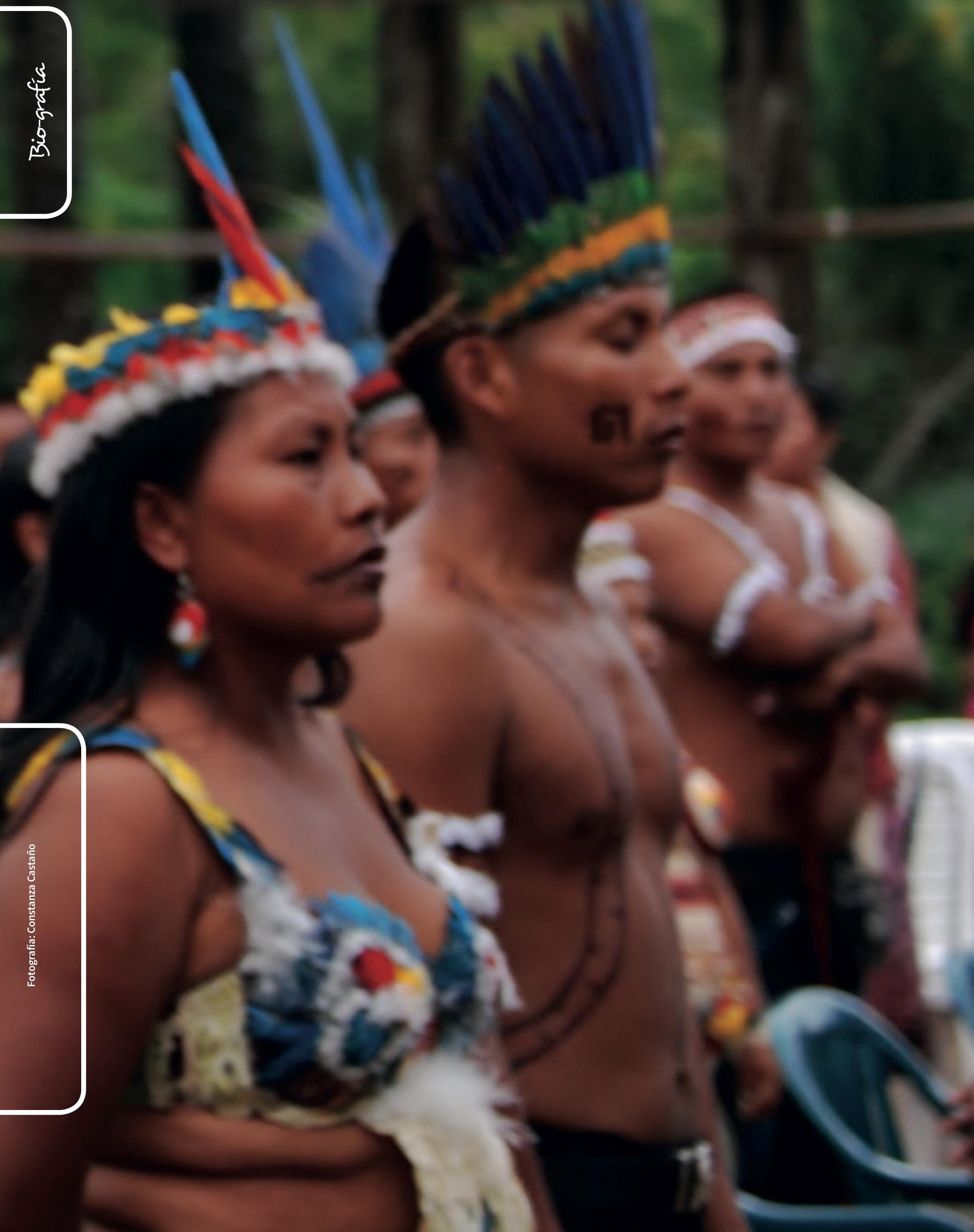




\section{EDUCACIÓN AMBIENTAL PARTICIPATIVA CON NIÑOS Y NIÑAS DE CUYUXQUIHUI, PAPANTLA, VERACRUZ: UN PROCESO EDUCATIVO ORIENTADO A LAS SELVAS DE LA LOCALIDAD}

\section{Participatory Environmental Education with children from Cuyuxquihui, Papantla, Veracruz: an educational process aimed at the jungles of the community}

Fecha de recepción: 16 de agosto de 2013

Fecha de aprobación: 13 de diciembre de 2013

\author{
Francisco Javier Guardado Mendoza ${ }^{1}$ \\ Evodia Silva Rivera²
}

La educación ambiental (EA) es un proceso educativo con el cual se busca inducir en las personas cambios conductuales y actitudinales a favor del ambiente que les rodea. De acuerdo a González-Gaudiano (1999), los objetivos de este proceso educativo no se reducen a tratar de que los individuos adquieran más y mejores conocimientos sobre el entorno biofísico, sino que se debe buscar cambiar paradigmas y comportamientos de la sociedad para mejorar la relación de esta con el ambiente y entre los mismos individuos. Otro aspecto importante es que la EA no se trata solo de buscar conservar la naturaleza o concientizar personas; sus objetivos deben ser más profundos y comprometidos; se debe aspirar a cambiar a la sociedad mediante la búsqueda de más y mejores condiciones de perdurabilidad, equidad y responsabilidad global (Caride y Meira, 2001). En este sentido, la EA debe concebirse como una práctica social crítica, estratégica y coherente que promueva alternativas que revolucionen el pensamiento y la acción de las personas.

La EA puede ser una herramienta de gran utilidad para lograr cambios en los niños y niñas a favor del ambiente, ya que las etapas de desarrollo en las que se encuentran estos grupos de población se caracterizan por una proclividad y un interés hacia el aprendizaje, lo cual facilita los procesos educativos. Barraza y Ceja-Adame (2003) afirman que es en estas etapas de desarrollo que los individuos adquieren las actitudes ambientales. Esta estrategia es aún más efectiva si las actividades educa-

1. Maestro en Ecología Tropical por el Centro de Investigaciones Tropicales de la Universidad Veracruzana. Ex. Had. Lucas Martín, Xalapa, Ver. Tel. 228-161-78-77. Correo electrónico: fjavierguardado@hotmail.com (autor de correspondencia)

2. En Estudios del Desarrollo por la University of East Anglia, Reino Unido. Actualmente docente e investigadora del Centro de Investigaciones Tropicales de la Universidad Veracruzana. Ex. Had. Lucas Martín, Xalapa, Ver. Tel. 228-1195174. Correo electrónico: esilva@gmail.com 
tivas son prácticas y si se realizan en campo, ya que esto facilita que los infantes adquieran conceptos ambientales y ejerzan su pensamiento crítico discutiendo problemas del entorno (Barraza, 2000). Adicionalmente, si dichos trabajos educativos se complementan con actividades participativas, se fomenta un mayor interés en los infantes por contribuir a la resolución de las problemáticas ambientales que les afectan. Sobre este mismo tema, Titman (1994) señala que diversas investigaciones realizadas alrededor del mundo indican que la participación de niños y jóvenes en los proyectos comunitarios ha contribuido a que dichos grupos de población adquieran y demuestren un sentido de mayor de responsabilidad por el cuidado y la conservación de su entorno.

La comunidad de Cuyuxquihui, ubicada en el municipio de Papantla de Olarte, en el estado de Veracruz, experimenta diversos problemas ambientales que son reflejo de los fenómenos de deterioro ambiental que afectan a una parte importante del país. Entre algunos de estos problemas se encuentra la deforestación de las selvas del ejido, el saqueo clandestino de fauna de esos ecosistemas y la contaminación provocada por la generación e incineración de residuos sólidos. Enfatizando en el problema de la deforestación, es importante explicar que este fenómeno ha propiciado una gradual reducción y fragmentación del hábitat de muchas especies de flora y fauna de la zona. Lo anterior, sumado al saqueo clandestino de fauna que se realiza en el lugar, ha provocado una disminución progresiva de las poblaciones de varias especies de animales de la localidad. Además, de acuerdo a los habitantes del lugar, en los últimos años la región ha experimentado cambios inusuales en las temperaturas y en la precipitación fluvial, registrándose temporadas con más calor y mayores periodos de sequía, fenómenos que, con frecuencia, se asocian a los procesos de deforestación (Conafor, 2011; García, 2011).

Considerando dichos escenarios, se diseñaron dos talleres de Educación Ambiental Participativa (EAP) dirigidos a los niños y niñas de Cuyuxquihui y orientados a las selvas y la vegetación de la localidad. Con las actividades realizadas en cada uno de los talleres se buscó que estos grupos de población participaran en diferentes actividades educativas teórico-prácticas con la finalidad de reforzar en ellos el interés y el valor hacia esos importantes ecosistemas.

\section{El sitio de estudio}

Cuyuxquihui es una comunidad totonaca cuyos orígenes se remontan al año de 1240 d. C. (Ruiz, 2010; Ruiz y García, 2010; Méndez et al., 2011). De acuerdo al Instituto Nacional de Estadística y Geografía (2010), esta comuni- dad se conforma en la actualidad por 598 habitantes, de los cuales 298 son hombres y 300 son mujeres. De estas personas, 208 tienen entre 0 y 18 años, 286 entre 18 y 60 años, y 104 son mayores de 59 años. La localidad se ubica en el municipio de Papantla de Olarte, en el estado de Veracruz, y se localiza en los $97^{\circ} 14^{\prime \prime} 52^{\prime}$ longitud oeste y $20^{\circ} 17^{\prime \prime} 00^{\prime}$ latitud norte, a una altura aproximada de 190 msnm en la región del Totonacapan (mapa 1).

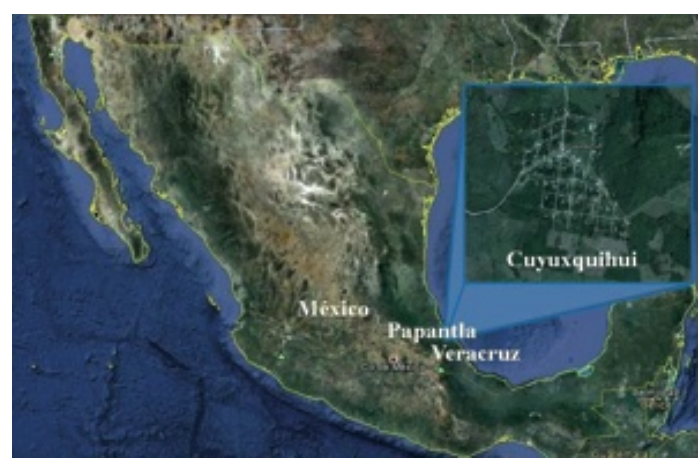

Mapa 1. Ubicación geográfica de Cuyuxquihui Fuente: Elaboración propia a partir de Google Earth.

El lugar cuenta con una escuela preescolar, una primaria y una telesecundaria. En preescolar los niños reciben educación en español y muy poco en lengua totonaca (solo el Himno Nacional). En la escuela primaria y telesecundaria la educación que se imparte es completamente en español. Además, en el sitio existe una zona arqueológica y un museo comunitario que lleva por nombre Serafín Olarte.

En el ejido de esta comunidad se llevan a cabo actividades agrícolas $\mathrm{y}$, en menor medida, actividades pecuarias como principal medio de subsistencia. En relación a la agricultura, productos como el maíz (Zea mays), el plátano (Musa paradisiaca), la naranja (Citrus sinensis), la vainilla (Vanilla sp.), el lichi (Litchi chinensis), el frijol (Phaseolus vulgaris), el chile (Capsicum annuum), el ajonjolí (Sesamum indicum L.), el tomate (Solanum lycopersicum), las calabazas (Cucúrbita pepo L.) y el cilantro (Coriandrum sativum) son la base de la subsistencia y de la economía de los pobladores de este lugar. La mayor parte de lo que los agricultores producen en las tierras del ejido es para autoconsumo; sin embargo, si se producen buenas cosechas por temporada, los excedentes son comercializados y contribuyen a la economía de los habitantes de la localidad. Por otro lado, y en relación con las actividades pecuarias, en algunas de las parcelas del lugar se tiene ganado bovino "de cría", cuyos ejemplares jóvenes o adultos son utilizados para venta. 


\section{Actividades preparativas para los talleres de EAP}

Durante el mes de mayo de 2012 se llevaron a cabo reuniones con distintos miembros de la comunidad de Cuyuxquihui, con la finalidad de informar sobre los detalles de las actividades y con el objetivo de pedir el respaldo de la población que directa o indirectamente se relacionaría a este trabajo. Primero, se habló con las autoridades del lugar (Agente Municipal, Comisariado Ejidal, Consejo de Vigilancia y secretarios de las autoridades), así como con los miembros y representantes del Consejo de los Abuelos del pueblo para pedir autorización para trabajar con los niños y niñas del pueblo. En este sentido, las autoridades y los ancianos de la comunidad, además de apoyar este trabajo, también externaron su agrado por involucrar a la niñez en este tipo de actividades.

Posteriormente, en compañía del agente municipal del pueblo, se visitó el kínder, la escuela primaria y la telesecundaria del lugar para pedir el apoyo de los maestros y directores de las escuelas para realizar algunas actividades en las instalaciones de los centros escolares; en este caso también se obtuvo el respaldo requerido.

Después, se realizó una reunión con los padres y madres de familia de los niños y niñas del pueblo, a los cuales se les informó acerca de las características y objetivos de este trabajo y se les pidió apoyo para involucrar a los infantes en este proceso. Al respecto, ellos, al igual que las autoridades de la comunidad, no únicamente brindaron su respaldo y apoyo para trabajar con los niños y niñas, sino que, además, expresaron su gusto y agradecimiento por involucrar a la niñez del pueblo en este tipo de actividades.

Una vez obtenido el apoyo y el permiso de las autoridades, de los maestros y directores de las escuelas, así como de los padres y madres de familia de los niños y niñas del pueblo, se realizó una visita a los alumnos de $4^{\circ}, 5^{\circ}$ y $6^{\circ}$ grado de la escuela primaria, así como a los alumnos de $1^{\circ}, 2^{\circ}$ y $3^{\circ}$ de la escuela telesecundaria. A estos grupos de niños y niñas se les informó que se había hablado con los padres y madres de familia sobre este proyecto, se les explicó las características de los talleres de EA y se les invitó a formar parte de este proceso educativo. La respuesta de los infantes fue positiva, ya que de 65 alumnos con los que se habló, 56 mostraron su interés por participar, siendo aproximadamente 40 niños y niñas los que se integraron en distintos momentos a las diferentes etapas de este proyecto. Cabe mencionar que, debido a que algunos de los infantes que participaron en este trabajo eran de turnos escolares diferentes, o a que algunos tenían distintas tareas extraescolares o diversas labores en su vida diaria en la comunidad, no todos pudieron estar al mismo tiempo en algunas de las actividades realizadas; lo anterior se resolvió llevando a cabo diferentes etapas de los talleres educativos por la mañana y por la tarde, a fin de facilitar la participación de los niños y niñas en dichas actividades.

\section{Diseño de los talleres de EAP}

Considerando el número de niños y niñas que se interesaron en participar en este trabajo, las edades de los infantes y las características del ambiente local y sus problemáticas asociadas, se diseñaron dos talleres de EAP, los cuales fueron impartidos del 1 al 8 de noviembre de 2012 y del 25 de noviembre al 4 de diciembre del mismo año. En estos talleres se implementaron actividades lúdico-educativas y actividades prácticas de eap en campo. Con relación a las actividades lúdicas, estas tuvieron diferentes funciones, por ejemplo: preparar a los niños y niñas para las tareas que se realizarían, promover armonía entre ellos, propiciar su integración, involucrarlos en las actividades realizadas, hacer más divertidos y dinámicos los momentos que pasaban dentro del aula y que disfrutaran de momentos de descanso sin dejar de aprender. Cabe mencionar que el grupo de participación estuvo conformado por niños y niñas tanto de la comunidad de Cuyuxquihui, como por niños y niñas no nativos de la comunidad que en algún momento llegaron a vivir a la localidad. Esto significó la presencia de niños y niñas de distintas culturas en el mismo grupo. Lo anterior nos llevó a fomentar la interculturalidad con los infantes mediante actividades basadas en el respeto y la igualdad, sin asimetrías, en las que ningún grupo cultural se asumiera por encima de los otros (Schmelkes, 2005). Por otro lado, respecto a las actividades de campo, dichas tareas tuvieron dos objetivos: 1) involucrar a los infantes en actividades prácticas directamente en la naturaleza, buscando generar procesos de reforzamiento de intereses y de valores ambientales en y sobre el entorno natural local y, 2) propiciar un proceso de investigación participativa que les permitiera aprehender la información generada. A continuación se describen las características de las actividades realizadas y el objetivo específico de cada tarea.

\section{Actividades lúdico-educativas}

Presentación y dinámica: Viaje por el Universo, Viaje por mi Comunidad. En esta actividad participaron 40 niños y niñas. Consistió en una exposición de fotografías interrelacionadas del universo, la galaxia, el sistema solar, el planeta Tierra, el continente americano, el territorio de México, el estado de Veracruz, Papantla, el ejido de Cuyuxquihui y diversas fotografías de sitios importantes de la localidad. El objetivo fue que los infantes, además 
de conocer, reconocer y vincular diversos lugares de su universo y su mundo, participaran tratando de conocer, reconocer y señalar en las diapositivas proyectadas el universo, su mundo y su comunidad.

Presentación y dinámica: Subasta de Valores. En esta actividad participaron 40 niños y niñas. Se buscó que los infantes se involucraran en un ejercicio que les ayudara a reflexionar sobre la importancia de diversos valores humanos que son necesarios para una sana convivencia. Para esto se les repartió dinero de papel a cada uno de ellos y se les explicó que se presentarían una serie de diapositivas con los títulos de diversos valores humanos los cuales podrían ser "comprados" mediante subasta. De esta forma, en una diapositiva se proyectaron todos los valores, y se les pidió a los niños y niñas que reflexionaran sobre cada uno de ellos y que pensaran en cuál valor les gustaría comprar. Finalmente, se les presentó un valor a la vez, desarrollándose de esta forma la subasta de valores.

Presentación y dinámica: Contraste de valores con imágenes y fotografías. Esta actividad fue complementaria a la anterior, y se buscó que mediante imágenes y fotografías que representaban valores humanos positivos y negativos, los niños y niñas aplaudieran o abuchearan lo que las imágenes reflejaban, al mismo tiempo que daban su opinión sobre la razón de su aprobación o desaprobación.

Dinámica: ¿Quién soy? En esta actividad participaron 12 infantes. Consistió en que los participantes reflexionaran sobre la fauna de su comunidad de una manera lúdica. Para ello, un voluntario pasaba al frente del grupo, y otro escribía en secreto sobre papel el nombre de un animal de la selva y se lo pegaba en la frente al primero. Entonces, este último, dando características de algún animal, trataba de adivinar "qué animal era", mientras los demás niños y niñas asentían o disentían, hasta que este lograba develar el secreto.

Exposición de videos ambientales. En esta dinámica participaron entre 20 y 35 niños y niñas. Tuvo como objetivo que los infantes reflexionaran y se enriquecieran mediante el intercambio de opiniones sobre diversos mensajes acerca del cuidado del medio ambiente y los valores humanos reflejados en videos ambientales animados que se les presentaron.

Dinámica: Juego de las calabazas. En este juego, sugerido por los niños y niñas, participaron entre 18 y 25 infantes. Consistió en que los integrantes formáramos un gran círculo tomados de la mano, mientras que dos de ellos (también tomados de la mano) corrían por fuera del círculo hasta que decidían cortarlo en algún lugar.
Entonces, los dos que quedaban separados corrían por la parte externa del círculo en dirección contraria a los primeros dos, compitiendo por llegar primero a cerrar el círculo, y así, sucesivamente. Con esta actividad se propició un ambiente de unión y armonía entre todos los participantes.

\section{Actividades de Educación Ambiental Participativa en campo y algunos resultados}

Fabricando composta. En esta actividad participaron 25 niños y niñas. Se buscó que, además de aprender a aprovechar residuos orgánicos producidos tanto en sus hogares como en los solares de su comunidad para generar composta, los infantes también reflexionaran sobre la problemática de la sobreproducción de residuos orgánicos e inorgánicos que se lleva a cabo en todo el mundo como consecuencia de los hábitos de consumo de las sociedades actuales y el daño que esto produce al ambiente. Para esta actividad, de manera previa se les pidió a los niños y niñas conseguir un bote para la elaboración de la composta y diversos materiales orgánicos desechados en sus casas; los infantes consiguieron un bote con tapa de aproximadamente 60 litros de capacidad, el cual se pudo perforar gracias a una visita grupal que se llevó a cabo a la carpintería comunitaria. Posteriormente, el bote contenedor se llenó con los diversos materiales orgánicos conseguidos por los niños y niñas, y con distintos materiales adicionales necesarios para la producción de composta. Finalmente, de entre los participantes, se eligieron voluntarios para que fueran los responsables de cuidar la composta y de mantenerla en condiciones de humedad. Es importante mencionar que, en acuerdo con los niños y niñas participantes, se decidió que la composta producida con esta actividad sería utilizada posteriormente para una práctica de reforestación que posteriormente se llevaría a cabo.

Aprendiendo a herborizar. En esta actividad participaron 29 niños y niñas. Tuvo dos propósitos: 1) que los infantes se acercaran a la vegetación de la localidad para reflexionar sobre algunos de los significados culturales que tiene dicha vegetación y, 2) que los niños y niñas participaran en la generación y aporte de material educativo-cultural para el museo comunitario de su comunidad. Así, se explicó a los participantes la dinámica del proceso que con esta actividad se llevaría a cabo y se enfatizó en que reflexionaran sobre las plantas que se herborizarían; es decir, se les hizo ver la importancia de que los ejemplares colectados tuvieran algún significado cultural local. Como resultado de esta actividad, los infantes reconocieron diversas plantas y su vínculo con la cultura, y participaron en la colecta y herborización de las siguientes plantas: Noche Buena (Euphorbia pulcherrima), Tepeji- 
lote (Chamaedorea sp.), Flor de Muerto o Cempasúchil (Tagetes erecta) y, por sugerencia personal, una ramita del árbol de Cuyuxquihui (Aphanante monoica). ${ }^{3}$ Finalmente, en grupo se acudió a la carpintería de la comunidad para hacer la petición de marcos de madera para proteger las plantas herborizadas para posteriormente colocarlas en el museo comunitario.

¿Qué frutales y qué plantas medicinales existen en Cuyuxquihui? En esta actividad participaron 32 niños y niñas. Se buscó que los infantes identificaran los frutales y las plantas medicinales que existen en su comunidad y que reflexionaran sobre la importancia de estos elementos naturales. De esta manera, por medio de dos salidas de campo, se visitaron varios solares del pueblo y se identificaron diversas plantas frutales y medicinales presentes en el lugar. Como resultado de estas actividades, los niños y niñas identificaron y elaboraron un listado de 66 frutales y 75 plantas medicinales.

Caracterizando el campo de Cuyuxquihui. En esta actividad participaron 34 infantes. Tuvo dos objetivos: 1) promover un acercamiento entre los niños y niñas y los padres y/o abuelos dueños de las parcelas del ejido a fin de promover una reflexión y transmisión de saberes de padres/abuelos a hijos/nietos sobre las actividades productivas que los primeros llevan a cabo en la zona y sobre los elementos que le dan estructura a las parcelas del ejido; y 2) que los niños y niñas se enriquecieran de información que les ayudara a comprender de mejor manera de qué elementos están constituidas las parcelas de sus padres y abuelos y qué actividades se llevan a cabo en la zona. Para esto, la actividad consistió en que, con la ayuda del padre o abuelo (ejidatario dueño de la parcela, en cualquier caso), los niños y niñas dibujaran y colorearan en una hoja la parcela de sus padres o abuelos. En dicho dibujo tenían que ser incluidos los elementos más importantes que le dan forma a la parcela dibujada, es decir, fragmentos de selva, cultivos presentes en el lugar, lomeríos, ganadería, pastizales, arroyos, manantiales, etc.

Mural. En esta actividad participaron 24 niños y niñas. Consistió en que estos dibujaran elementos naturales y culturales característicos de su comunidad sobre cartulinas blancas colocadas en un espacio habilitado en

3. La colecta de esta planta fue posible gracias a un ejidatario de la comunidad (José Galindo), quien posee uno de los mayores fragmentos de selva mediana del ejido (10 hectáreas). Este ejidatario amablemente donó para los trabajos de esta investigación no solamente un pequeño ejemplar de Aphanante monoica para su herborización, sino, además, algunos árboles requeridos para la actividad de reforestación que se llevaría a cabo como parte de este trabajo. la escuela primaria del pueblo. El objetivo fue que los infantes expresaran, mediante dibujo, los elementos naturales y culturales más importantes para ellos.

Reforestación. En esta actividad participaron 28 niños y niñas. Tuvo como objetivo involucrar a estos grupos de población en un ejercicio de reforestación comunitaria. Para el momento de llevar a cabo este ejercicio, ya se habían realizado las actividades lúdicas educativas y prácticas de campo que contribuyeron a introducir y a preparar a los infantes para dicha tarea. Es decir, cada una de las actividades anteriores tuvo el propósito de detonar en los niños y niñas procesos de reflexión sobre las selvas de su comunidad y la importancia de conservar estos ecosistemas. De esta forma, la tarea comenzó consiguiendo un solar en donde se pudieran sembrar los árboles elegidos y en donde los niños y niñas pudieran cuidarlos durante el tiempo en que, por cuestiones relacionadas a la calendarización de actividades del presente trabajo, tuviera que estar detenida esta tarea. Después, con la participación de los infantes, se procedió a realizar las excavaciones en donde se sembrarían algunos de los árboles que se pudieron conseguir. Una vez realizado lo anterior, y de manera casi inmediata, con la guía y apoyo de un ejidatario de la comunidad (dueño de uno de los fragmentos de selva más grandes del ejido en donde aún existen los arboles Cuyuxquihui [Aphanante monoica]) y con la ayuda de algunos jóvenes voluntarios del pueblo, se llevó a cabo una salida de campo para obtener cuatro ejemplares de dicho árbol. Es importante mencionar que la elección de esta especie de árboles para ser incluida en la actividad de reforestación, obedece a razones culturales. Es decir, debido a que esta especie de árboles es el símbolo cultural de la comunidad y que, paradójicamente, muy pocas personas del pueblo conocen, se consideró apropiado y pertinente que esta fuera una de las especies utilizadas para dicho ejercicio. De esta forma, el mismo día que se obtuvieron los ejemplares del árbol de Cuyuxquihui, con la ayuda de los niños y niñas se sembraron los cuatro ejemplares de dicha planta y, además, se hizo un recorrido por el pueblo para conseguir cinco ejemplares de árboles de mango, los cuales fueron donados por una pobladora del lugar.

Convivios. Finalmente, el último día de cada una de las dos semanas en que se realizaron los talleres, se llevó a cabo una comida de despedida y se presentó una película y un documental con mensajes sobre el cuidado ambiental. En la medida de lo posible, se buscó que estos convivios fueran organizados por los niños y niñas para propiciar su participación e integración. En estas actividades participaron 20 y 28 niños y niñas en el primer y segundo convivio respectivamente. 


\section{A manera de conclusión}

Las actividades de EAP planeadas con los niños y niñas de la comunidad de Cuyuxquihui fueron pertinentes, ya que se diseñaron de acuerdo a los contextos ambientales de la localidad, considerándose para ello las características del ambiente local y las problemáticas asociadas. La familiaridad que para los niños y niñas tuvieron los elementos en torno a los cuales se diseñaron dichas actividades (selvas, fauna, agricultura y problemas ambientales locales) facilitó que los infantes comprendieran las diferentes tareas propuestas y propició que respondieran adecuadamente a los ejercicios desarrollados. Lo anterior se constató con la respuesta entusiasta, comprometida y participativa de los infantes, misma que permitió obtener los resultados favorables que se explicaron en párrafos anteriores. Dichos resultados podrían considerarse un indicador de que este proceso contribuyó al fortalecimiento e interés de los niños y niñas con relación al conocimiento y cuidado del ambiente de su localidad. $Y$ aunque los resultados y/o beneficios que este proceso puede generar sobre el ambiente local solo pueden ser evaluados a mediano o largo plazo, por el momento podemos argumentar que a lo largo de las actividades desarrolladas, los niños y niñas que participaron en esta experiencia educativa mostraron actitudes y conductas ambientalmente responsables. Por tal motivo, consideramos que el objetivo principal de esta experiencia educativa se cumplió.

De esta manera, el presente trabajo nos enseñó que procesos de eap con grupos de población infantil y contextualizados de acuerdo con las características de las localidades pueden contribuir al fortalecimiento del interés por el ambiente y a la disposición de participar en acciones a favor del mismo, lo cual podría representar un paso importante que facilite procesos de protección y conservación de diferentes elementos ambientales, entre los que se encuentran los ecosistemas forestales, procesos en los que los niños y las niñas pueden participar activamente.

Es importante señalar que gran parte del interés que los niños y niñas de Cuyuxquihui mostraron por el ambiente no es propiciado por la escuela, ya que en el aula los infantes no reciben educación sobre su ambiente local de manera específica. Esto nos lleva a suponer que gran parte de su interés ambiental es producto de la interacción que tienen con su entorno y de las experiencias que comparten con los adultos con los que conviven, principalmente los padres y abuelos. Por tal motivo, es necesario desarrollar estrategias que permitan dar continuidad a los procesos que contribuyen a desarrollar los valores a favor del ambiente en los niños y niñas. Tales procesos pueden enriquecerse con la promoción desde la escuela del conocimiento del ambiente local a través de salidas de campo continuas, ya que, de acuerdo con nuestra experiencia, estas actividades pueden ayudar a fortalecer y enriquecer los conocimientos y el interés que sobre el entorno inmediato tienen los niños, y a que estos los aprehendan más profundamente. Asimismo, es fundamental que las generaciones adultas continúen compartiendo sus saberes tradicionales con las generaciones más jóvenes, ya que esto contribuiría a fortalecer los conocimientos y el interés que estos grupos de población generan al interactuar con su ambiente.

Para concluir, es fundamental que en comunidades como esta se diseñen acciones educativas con objetivos a corto, mediano y largo plazo orientados a cuidar, conservar y proteger el ambiente. Para ello, es necesario partir de una visión en la que estén contemplados los niños y niñas, a fin de que se puedan sembrar acciones que faciliten resultados concretos y duraderos para que estos grupos de población puedan tener entornos comunitarios más saludables y propiciar mejores condiciones de vida para las generaciones futuras.

\section{Referencias}

Barraza, L. (2000). Educar para el futuro: en busca de un nuevo enfoque de investigación en Educación Ambiental. En Memorias Foro Nacional de Educación Ambiental (pp. 253-260). Aguascalientes: uaa, SEPy semarnap.

Barraza, L. y Ceja-Adame, M. P. (2003). Los niños de la comunidad: su conocimiento ambiental y su percepción sobre la "naturaleza". En A. Velázquez, A. Torres y G. Bocco (Comp.), Las enseñanzas de San Juan. Investigación participativa para el manejo integral de recursos naturales (pp. 371-398). México, D.F.: ine-semarnat.

Caride, J. A. y Meira, P. A. (2001). Educación ambiental y desarrollo humano. Barcelona: Ariel.

Comisión Nacional Forestal (Conafor) (Mayo, 2011). Taller sobre estimación de los costos de oportunidad y costos de implementación para el proceso de planificación nacional. Trabajo presentado en el Taller Regional para América Latina, Cali, Colombia.

Convención sobre los Derechos del Niño. Adoptado por la Organización de las Naciones Unidas, el 20 de noviembre de 1989. Extraído el 20 de diciembre de 2012, de http://www.cndh.org.mx/sites/all/fuentes/documentos/Programas/Discapacidad/Conv_ DNi\%C3\%B1o.pdf 
García, M. (2011). Cambio climático, calentamiento global y pueblos indígenas en México. Maderas del Pueblo del Sureste, A. C. Pacto de grupos ecologistas. Extraído el 6 de julio de 2012, de http://www.maderasdelpueblo.org. mx/archivos/estcambclimyterrpifmtoedit_0.pdf

González-Gaudiano, E. (Mayo 30, 1999). El ambiente: mucho más que ecología. El Universal. Extraído el 5 de enero de 2012, de http://anea.org.mx/docs/ Gonzalez-EcologiayMedioAmb.pdf.

Instituto Nacional de Estadística y Geografía (2010). Censos y conteos de población y vivienda. Censo de población y vivienda 2010. Extraído el 10 de enero de 2011, de www.censo2010.org.mx

Méndez, P., Cortés, R., Cortés, L., Atzin, M., Morales, A., Atzin, H., Vázquez, E., Cortés, R. et al. (2011). Cuyuxquihui: breve historia de la localidad. México: Culturas Populares, Conaculta.
Ruiz, O. (2010). Cuyuxquihui, municipio de Papantla. En S. Vázquez, H. Bernard y S. Ladrón de Guevara (Coords.), La morada de nuestros ancestros: Alternativas para la conservación (pp. 91-100). Xalapa, Veracruz, México: Consejo Veracruzano de Investigación Científica y Desarrollo Tecnológico.

Ruiz, O. y García, D. (2010). Cuyuxquihui: Patrimonio Culturaly Natural de Totonacapan. México: Conaculta.

Schmelkes, S. (Enero, 2005). La interculturalidad en la educación básica. Conferencia presentada en el Encuentro Internacional de Educación Preescolar: Currículum y Competencias, México, D.F.

Titman, W. (1994). Special Places; Special People: The Hidden Curriculum of School Grounds. UK: World Wide Fund for Nature. 